\title{
A falta de inserção do Parque Estadual do Espinilho enquanto espaço de formação ambiental
}

\author{
The lack of insertion of the Espinilho State Park as a space for \\ environmental training
}

\section{La falta de inserción del Parque Estatal de Espinilho como espacio de entrenamiento ambiental}

\author{
Allyson Henrique Souza Feiffer ${ }^{1 \mathbb{D}}$; Fernando Icaro Jorge Cunha ${ }^{\mathbb{D}}$; \\ Leonardo Barboza Benites $^{3}{ }^{\mathbb{D}}$; Ailton Jesus Dinardi ${ }^{(\mathbb{D}}$
}

\section{RESUMO}

Este projeto objetivou analisar a visão dos educandos do ensino fundamental (ciclo final) sobre o Parque Estadual do Espinilho (PEE) com o intuito de se desenvolver uma proposta de aproximação dos educandos e da comunidade escolar com o PEE através da promoção da Educação Ambiental. O trabalho foi desenvolvido no ano de 2018, em parceria com a Escola Estadual de Ensino Médio Nilza Corrêa Pereira (Barra do Quaraí-RS), com estudantes de duas turmas do ensino fundamental II, uma turma do $6^{\circ}$ ano (ano inicial deste ciclo), com 14 educandos e de uma turma do $9^{\circ}$ ano (ano final do ciclo) com 17 educandos, através da aplicação e análise de um questionário com quatro questões abertas. Como resultados pode-se inferir que os educandos desconhecem a área do $\mathrm{PEE}$, que o conceito de seres vivos presentes no parque são retratados na forma de animais, porém de animais exóticos, pertencentes a outros biomas. Como considerações finais observa-se que o PEE não é utilizado enquanto espaço de ensino pela escola, sendo que o desenvolvimento de projetos que envolvam esta unidade de conservação, como instrumento para a promoção da Educação Ambiental e reflexão sobre as questões regionais, a partir da biodiversidade vegetal e animal faz-se necessário.

Palavras-chave: Diversidade Vegetal; Ensino; Potencialidades; Desenhos.

\begin{abstract}
This project aimed to analyze the vision of elementary school students (final cycle) about the Espinilho State Park (PEE) in order to develop a proposal to bring students and the school community closer to the PEE through the promotion of Environmental Education. The work was developed in 2018, in partnership with the Nilza Correa Pereira State High School (Barra do Quarai-RS), with students from two classes of elementary school II, one class from the 6th year (initial year of this cycle), with 14 students and a 9th grade class (final year of the cycle) with 17 students, through the application and analysis of a questionnaire with four open questions. As a result, it can be inferred that students are unaware of the PEE area, that the concept of living beings present in the park are portrayed in the form of animals, but exotic animals belonging to other biomes. As final considerations, it is observed that the PEE is not used as a teaching space by the school, and the development
\end{abstract}

\footnotetext{
${ }^{1}$ Licenciado em Ciências da Natureza, Especialista em Avaliação de Impactos Ambientais e Processos de Licenciamento Ambiental e em Educação Ambiental na Universidade Federal do Pampa (UNIPAMPA), Uruguaiana/RS - Brasil. E-mail: allysonfeiffer@gmail.com

${ }^{2}$ Licenciando em Ciências da Natureza na Universidade Federal do Pampa (UNIPAMPA), Uruguaiana/RS - Brasil. E-mail: icaro729@gmail.com

${ }^{3}$ Licenciado em Ciências da Natureza na Universidade Federal do Pampa (UNIPAMPA), Uruguaiana/RS - Brasil. E-mail: leonardo-280898@live.com

${ }^{4}$ Graduado em Ciências Habilitação em Biologia, Especialista em Educação Ambiental, Mestre em Educação para Ciências, Doutora em Ciência Florestal pela UNESP e Professor Adjunto da Universidade Federal do Pampa (UNIPAMPA), Uruguaiana/RS - Brasil. E-mail: ailtondinardi@gmail.com
} 
of projects involving this conservation unit, as an instrument for the promotion of Environmental Education and reflection on issues regional, from plant and animal biodiversity is necessary.

Keywords: Plant diversity; Teaching; Potentials; Drawings.

\section{RESUMEN}

Este proyecto tuvo como objetivo analizar la visión de los estudiantes de primaria (ciclo final) sobre el Parque Estatal Espinilho (PEE) con el fin de desarrollar una propuesta para acercar a los estudiantes y la comunidad escolar al PEE a través de la promoción de la Educación Ambiental. El trabajo se desarrolló en 2018, en alianza con la Escuela Secundaria Estatal Nilza Corrêa Pereira (Barra do Quaraí-RS), con estudiantes de dos clases de la escuela primaria II, una clase del $6^{\circ}$ año (año inicial de este ciclo), con 14 alumnos y una clase de $9^{\circ}$ curso (último curso del ciclo) con 17 alumnos, mediante la aplicación y análisis de un cuestionario con cuatro preguntas abiertas. Como resultado, se puede inferir que los estudiantes desconocen el área de PEE, que el concepto de seres vivos presentes en el parque están retratados en forma de animales, pero animales exóticos pertenecientes a otros biomas. Como consideraciones finales, se observa que el PEE no es utilizado como espacio de enseñanza por parte de la escuela, y el desarrollo de proyectos que involucren esta unidad de conservación, como instrumento para la promoción de la Educación Ambiental y la reflexión sobre temas regionales, desde la planta y la biodiversidad animal es necesaria.

Palabras clave: Diversidad vegetal; Enseñando; Potenciales; Dibujos.

\section{INTRODUÇÃO}

O Brasil é conhecido mundialmente pela sua imensa biodiversidade que pode ser explicada pela sua extensão territorial que abriga uma diversidade de ambientes com clima e cobertura vegetal singulares. Segundo Ricklefs (2011, p. 78), os biomas "são denominados a partir do agrupamento das comunidades biológicas e dos ecossistemas em categorias, levando-se em consideração a vegetação e o clima dominante, fatores responsáveis pela caracterização geral de cada bioma".

Segundo o Instituto Brasileiro de Geografia e Estatística (IBGE), um bioma pode ser definido por um:

Conjunto de vida (vegetal e animal) definida pelo agrupamento de tipos de vegetação contíguos e identificáveis em escala regional, com condições geoclimáticas similares e história compartilhada de mudanças, resultando em uma diversidade biológica própria (BRASIL, 2004, p. 49).

O Brasil, conta com seis biomas em seu território, definidos principalmente pela cobertura vegetal (BRUSCA; BRUSCA, 2005). Conforme dados encontrados na categoria 'Biodiversidade Brasileira' no website do Ministério do Meio Ambiente:

[...] o Brasil abriga a maior biodiversidade do planeta, apresentando seus diferentes biomas: a Floresta Amazônica, maior floresta tropical úmida do mundo; o Pantanal, maior planície inundável; o Cerrado de savanas e bosques; a Caatinga de florestas semiáridas; os campos dos Pampas; e a floresta tropical pluvial da Mata Atlântica. Além disso, o Brasil possui uma costa marinha de 3,5 milhões $\mathrm{km}^{2}$, que inclui ecossistemas como recifes de corais, dunas, manguezais, lagoas, estuários e pântanos.

Para proteger estes biomas, o governo instituiu as Unidades de Conservação (UC). Segundo a Lei Federal n 9.985 de 18 de julho de 2000, Unidades de Conservação são:

Espaço territorial e seus recursos ambientais, incluindo as águas jurisdicionais, com características naturais relevantes, legalmente instituído pelo Poder Público, com 
objetivos de conservação e limites definidos, sob regime especial de administração, ao qual se aplicam garantias adequadas de proteção (BRASIL, 2000, Art. 2).

Esta mesma lei instituiu o Sistema Nacional de Unidades de Conservação da Natureza - SNUC, constituído pelo conjunto das unidades de conservação federais, estaduais e municipais, sendo que as UC integrantes do SNUC dividem-se em dois grupos: Unidades de Proteção Integral e Unidades de Uso Sustentável.

Porém, do ponto de vista da conservação, apenas a delimitação destes espaços, denominados de UC não basta, visto que a ação educativa ambiental se faz necessária, seja através da educação formal, seja através da educação não formal. Cerati e Lazarini (2009), ressaltam a importância de se estabelecerem políticas públicas que fomentem a parceria entre instituições produtoras de saber e a educação formal a fim de promover a divulgação do conhecimento, atualização de professores, a melhoria da qualidade do ensino e a conscientização da população sobre a importância da conservação da biodiversidade.

Se realmente se almeja a emancipação e o despertar do vínculo e do pertencimento de uma sociedade com as causas ambientais, faz-se necessário fomentar a relação de aproximação entre os atores responsáveis pelo processo de ensino e aprendizagem e os espaços públicos e privados com potencial para o desenvolvimento da Educação Ambiental, pois já virou ditado popular: "não se preserva aquilo que não se conhece" (DINARDI; FEIFFER; FELIPPELLI, 2018). De acordo com Mota, Cousin e Kitzmann (2018, p. 215), o sentido válido de pertencimento é o "que aposta na emancipação humana e na transformação social, a partir da participação".

Com relação ao bioma Pampa, este abrange praticamente toda a metade Sul do Rio Grande do Sul, agrega muitos valores para a biodiversidade, com as suas particularidades que englobam uma vegetação campestre, com espécies arbóreas de pequeno porte, bem como, uma fauna rica e vasta com animais exóticos e raros, que constituem o patrimônio cultural brasileiro (BILENCA; MIÑARRO, 2004). Em termos de ocupação geográfica, o Pampa ocupa 62,2\% do Estado do Rio Grande do Sul, com cerca de $700.000 \mathrm{~km}^{2}$, além de alcançar parte do território Uruguaio e Argentino (BOLDRINI et al., 2010a).

No que se refere à atividade econômica, a pecuária extensiva sobre os campos nativos tem sido a principal atividade econômica da região. Neste sentido, as lavouras de arroz e soja são predominantes em produção agrícola e ascensão econômica regional (KUPLICH; CAPOANE; COSTA, 2018).

Heiden e Iganci (2016) descrevem que as paisagens naturais do pampa se caracterizam pelo predomínio dos campos nativos, mas há também a presença de matas ciliares, matas de encosta, matas de pau-ferro (cobertura vegetal arbórea que apresenta especificidades da Mata Atlântica como as plantas endêmicas), formações arbustivas, butiazais, banhados, afloramentos rochosos, dentre outras. O relevo deste bioma é caracterizado pela formação de serras e planícies, sendo este tipo de formação do relevo conhecido como "coxilhas do pampa gaúcho". O clima do Pampa é o clima subtropical, característico da região Sul do Brasil, clima chuvoso, sem um período seco sistemático, contudo, é marcado pela frequência de frentes polares e temperaturas negativas no inverno.

Estimativas indicam valores em torno de 3000 espécies de plantas e diferentemente dos demais biomas brasileiros, o Pampa possui uma vegetação dominada por gramíneas, plantas diversificadas pertencentes à família Poaceae (CAMINHA, 2010; CASTRO, 2018). 
Nas áreas de campo natural, também se destacam espécies da família Asteraceae e Fabaceae como a babosa-do-campo (Aloe vera L. Burm.f.), o amendoim-nativo (Arachis hypogaea L.) e o trevo-nativo (Oxalis tetraphylla). Nas áreas de afloramentos rochosos podem ser encontradas muitas espécies de cactáceas (MACHADO et al., 2013).

Apesar de possuir uma biodiversidade expressiva, desde a década de 70 o Pampa vem enfrentando o desenvolvimento em larga escala das monoculturas, bem como, o crescimento massivo de pastagens com espécies exóticas, contribuindo significativamente para a degradação do bioma (BOLDRINI et al., 2010b). Estes fatores supracitados, modificam o paisagismo natural e descaracterizam o naturalismo pampeano. Além disso, estima-se que em 2002 apenas 41,32\% do Pampa comtemplava a vegetação nativa e, em 2008 restavam apenas 36,03\% aproximadamente (BRASIL, 2010).

No Rio Grande do Sul, o Sistema Estadual de Unidades de Conservação (SEUC) abrange 23 Unidades de Conservação estaduais sob administração pública, duas Reservas Particulares do Patrimônio Natural e 27 Unidades de Conservação municipais cadastradas (MANDIÃO, 2012, p. 9). 0 SEUC originalmente foi criado pelo Decreto $n^{\circ} 34.256 / 1992$ e foi atualizado de acordo com o Sistema Nacional de Unidades de Conservação (SNUC), passando a ser regulamentado pelo Decreto $\mathrm{n}^{\circ}$ 53.037/2016 e constituindo-se pelo conjunto de Unidades de Conservação federais, estaduais, municipais e particulares criadas no território do Estado (RIO GRANDE DO SUL, 2016).

Dentre estas UC estaduais, foi criado em 1975 o Parque Estadual do Espinilho (PEE), com o objetivo de proteger ecossistemas significativos da paisagem rio-grandense. O PEE é uma Unidade Estadual de Proteção Integral, com 1.617,14 ha de área, localizada no bioma Pampa, no município de Barra do Quaraí, extremo sudoeste do Rio Grande do Sul, na divisa com o Uruguai e a Argentina.

A bibliografia encontrada na literatura é muito limitada, quando se trata de pesquisas, estudos e publicações em geral acerca do $\mathrm{PEE}$, corroborando para disseminação de diversos equívocos (MARCHIORI; ALVES; DEBLE; DEBLE, 2014). Esta crítica é muito preocupante, visto que, o parque constitui diversas potencialidades, que estende-se até mesmo ao âmbito da prática da Educação Ambiental. Sua nomenclatura é constituída pela cobertura arbórea vegetal do Espinilho, que agrega particularidades enriquecedoras na Botânica. Atualmente o parque encontra-se sob a proteção da Secretaria do Meio Ambiente e Infraestrutura (SEMA). Portanto, visitas ao parque e atividades científicas e educativas, podem ser realizadas com agendamento prévio e autorização.

Outro aspecto que distingue e valoriza o referido Parque, no conjunto das unidades
de conservação do Rio Grande do Sul, é seu numeroso contingente de espécies raras,
endêmicas e ameaçadas de extinção. Em contraste com sua importância científica no
contexto regional, a literatura sobre o Parque Estadual do Espinilho é marcada por
confusões e/ou graves equívocos (MARCHIORI; ALVES; DEBLE; DEBLE, 2014, p. 12).

Em 2002 o PEE foi ampliado por meio do Decreto $n^{\circ} 41.440 / 2002$, englobando áreas importantes para a conservação, incluindo parte do curso do arroio Quaraí-chico, até a sua foz com o rio Uruguai (RIO GRANDE DO SUL, 2002). O Parque é importante para a conservação de uma formação vegetal que só ocorre na região (savana estepe e savana parque), com espécies características, como o espinilho (Acacia caven), o algarrobo (Prosopis nigra) e o inhanduvá (Prosopis affinis).

Estudos realizados por Galvani e Baptista (2003) demonstram que, embora o parque exista há quase meio século, a riqueza vegetal do parque ainda é pouco estudada. A primeira referência aos 
ambientes que integram o Parque do Espinilho ocorreu em 1956 por Rambo, no seu diário de bordo e futuramente transformado em um livro intitulado Viagens ao Sudoeste do Rio Grande do Sul.

Segundo Galvani e Baptista (2003) foram catalogadas no PEE 72 espécies arbóreo-arbustivas, lianas e epífitos vasculares, distribuídas em 58 gêneros pertencentes a 32 famílias botânicas; 124 espécies herbáceas, distribuídas em 95 gêneros, pertencentes a 30 famílias botânicas e 59 espécies de macrófitas aquáticas (plantas aquáticas), distribuídas em 46 gêneros pertencentes a 32 famílias.

Nessa perspectiva, partindo do pressuposto de que há uma rica biodiversidade animal e vegetal no Parque Estadual do Espinilho e que a sede do município da Barra do Quaraí localiza-se a poucos quilômetros de distância desta unidade de conservação, podemos inferir o seguinte questionamento: qual o grau de conhecimento do PEE pela comunidade escolar local? Essas indagações fazem-se necessárias pois a Educação Ambiental, como um processo político, crítico e reflexivo, que de fato promova conhecimentos, atitudes e valores, precisa ser desenvolvida de forma contextualizada, partindo da realidade dos estudantes, pois só assim haverá mudanças e emancipação e entendemos que o PEE representa um excelente espaço de formação.

No Rio Grande do Sul, segundo a Lei no 15.434/2020, Art. 27:

Compete ao Poder Público promover a educação ambiental em todos os níveis de sua atuação e a conscientização da sociedade para a preservação, conservação e recuperação do meio ambiente, considerando: III - a necessidade das instituições governamentais estaduais e municipais de realizarem ações conjuntas para o planejamento e execução de projetos de educação ambiental, respeitando as peculiaridades locais e regionais (RIO GRANDE DO SUL, 2020, Art. 27).

Segundo Medeiros et al. (2011), a aplicabilidade da Educação Ambiental nas escolas se faz necessária, devido à enorme carência de conhecimento por parte da sociedade com relação ao conhecimento crítico direcionado à preservação ambiental, à sustentabilidade e à responsabilidade social.

Ainda de acordo com Correa (2008), o setor educacional é um dos principais responsáveis pelo negligenciamento do Pampa, a partir do momento em que começa a passar informações vagas sobre o bioma, contribuindo assim para o descaso com o meio ambiente.

Devido ao PEE estar inserido no bioma Pampa, é interessante que os educandos também possam conhecer o bioma presente em seu estado e em sua região, possibilitando maiores descobertas acerca da biodiversidade local. Entretanto, ressalta-se que as escolas muitas vezes "pecam" ao divulgar informações generalistas sobre o Pampa, ou muitas vezes nem mencionam algo relacionado a este bioma (SOUZA; DINARDI; PEREIRA, 2020).

Para Sauvé (2005), dentre as muitas Correntes da Educação Ambiental, o sentimento do pertencimento a um local pode ser explorado pela Corrente de Educação Ambiental denominada de Biorregionalista. A Corrente Biorregionalista se inspira geralmente numa ética ecocêntrica e centra a Educação Ambiental no desenvolvimento de uma relação preferencial com o meio local ou regional, no desenvolvimento de um sentimento de pertença a este último e no compromisso em favor da valorização deste meio.

Sendo assim, o presente trabalho objetiva analisar a visão dos educandos do ensino fundamental (ciclo final) sobre o Parque Estadual do Espinilho com o intuito de se desenvolver uma proposta de aproximação dos educandos e da comunidade escolar com o PEE através da promoção da Educação Ambiental. 


\section{METODOLOGIA}

O presente trabalho foi desenvolvido no ano de 2018, no município de Barra do Quaraí, extremo sudoeste do Rio Grande do Sul, em parceria com a Escola Estadual de Ensino Médio Nilza Corrêa Pereira e nas dependências do Parque Estadual do Espinilho com estudantes de duas turmas do ensino fundamental II, uma turma do $6^{\circ}$ ano (ano inicial deste ciclo), com 14 educandos e de uma turma do 90 ano (ano final do ciclo) com 17 educandos.

A pesquisa possui uma abordagem de caráter qualitativa, em que segundo Moreira (2011), a pesquisa qualitativa presume a coleta de dados mediante as influências mútuas que acontecem entre 0 pesquisador e o objeto de estudo. Nesse sentido de acordo com Minayo (2010), a pesquisa qualitativa visa à construção da realidade, se preocupando com as ciências em um nível de realidade que não pode ser quantificado, trabalhando com o universo de crenças, valores, significados e outros construtos profundos das relações que não podem ser reduzidos à operacionalização de variáveis.

Assim a atividade se desenvolveu nos seguintes momentos:

10) Primeiramente foi realizada uma visita a escola, com o intuito de apresentar a atividade aos professores e gestores da instituição, seguida de um primeiro contato com a turma que iria participar da atividade.

$2^{\circ}$ ) No primeiro contato com os discentes apresentou a proposta do trabalho a ser desenvolvido, com poucos detalhes sobre o Parque do Espinilho, pois a intenção era que os estudantes expressassem seus conhecimentos sobre o PEE.

Ainda nessa etapa foi lançada uma pergunta aos discentes, sendo "O que você entende por Unidades de Conservação?". Em seguida foi solicitado aos estudantes do $6^{\circ}$ ano e $9^{\circ}$ ano, que definissem o que era para eles as Unidades de Conservação (visando construir uma nuvem de palavras); também foi perguntado se já conheciam o Parque Estadual do Espinilho - PEE e caso a resposta fosse afirmativa, com quem haviam visitado o parque, e se achavam importante a conservação do Parque Estadual do Espinilho.

Após este questionamento foi solicitado aos estudantes do $6^{\circ}$ ano, o desenho de um "ser vivo", não sendo acrescentado mais nenhum detalhe sobre o desenho. Os desenhos foram solicitados a turma do $6^{\circ}$ ano devido a eles serem a primeira turma do ensino fundamental II e por eles ainda possuírem certa facilidade em expressar suas ideias de uma forma mais caricata, e os desenhos acabam por se tornar uma ferramenta bastante viável para esse mecanismo.

O desenho é um meio de conhecimento e seu uso não se restringe ao lápis e ao papel [...] desse modo, a criança explora espaços, percebe o mundo e se percebe nele. Assim, há que se pensar em arte não mais como representação fiel ou idealizada da natureza, mas como livre expressão. Uma educação pautada em concepções tradicionais de arte produz, mesmo que de maneira não intencional, a formação de sujeitos submissos, sem percepção de mundo, sem criatividade, presos a valores estabelecidos (MARTINS; GARCIA, 2014, p. 5).

Conforme Pillar (2012, p. 43), entende-se como desenho, todo trabalho gráfico "que não é resultado de uma cópia, mas da construção da interpretação que ela faz dos objetos, num contexto sociocultural e em uma época".

O modelo de questionário segue disponibilizado abaixo (Quadro 1). 
Quadro 1 - Disposição do questionário.

\begin{tabular}{|l|l|}
\hline \multicolumn{1}{|c|}{$\mathbf{N}^{\mathbf{0}}$} & \multicolumn{1}{c|}{ Questões } \\
\hline 1 & O que você entende por Unidades de Conservação? \\
\hline 2 & Você já visitou o PEE anteriormente? Se sim, com quem? \\
\hline 3 & Na sua opinião, a conservação do PEE é importante? \\
\hline 4 & Elabore um desenho de um ser vivo. \\
\hline
\end{tabular}

Fonte: Os autores.

\section{RESULTADOS E DISCUSSÃO}

A partir dos resultados obtidos com a primeira pergunta: $O$ que você entende por Unidades de Conservação? Foi possível organizar esta nuvem de palavras (Figura 1), verificando que a definição de Unidades de Conservação é algo que remete os estudantes ao que foi nominado, ou seja, a palavra conservação dá o tom das respostas, seguido das palavras árvore e estudos. Nenhum dos educandos relacionou o Parque Estadual do Espinilho a uma Unidade de Conservação.

Figura 1 - Nuvem de palavras construída a partir das concepções dos 31 educandos (14 educandos do $6^{\circ}$ ano e 17 educandos do $9^{\circ}$ ano) sobre Unidades de Conservação.

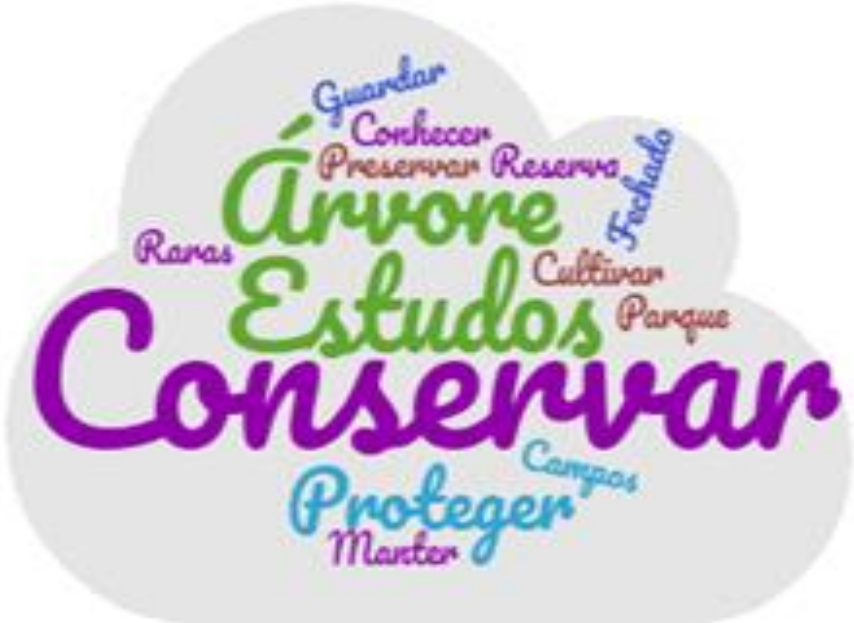

Fonte: elaborado pelos autores.

De acordo com fundamentos de Fonseca, Lamas e Kasecker (2010), é possível identificar a definição de Unidades de Conservação:

No Brasil as unidades de conservação (UCs) são a forma mais difundida de proteção. Inúmeras delas foram criadas no país com distintos objetivos e sob a gestão de diferentes órgãos. Mas até o final da década de 80 não existia no país um sistema de unidades de conservação com estrutura organizada e coesa [...] têm como objetivo primordial preservar a Natureza e admitem apenas o uso indireto dos recursos naturais [...] É preciso considerar que a maior parte da superfície protegida no Brasil é composta por unidades de conservação de uso sustentável, como Áreas de Proteção Ambiental (APA), onde diversas atividades humanas são permitidas, incluindo as que produzem profundos impactos ambientais, como a mineração e a indústria, e onde se incluem até mesmo núcleos urbanos (FONSECA; LAMAS; KASECKER, 2010, p. 18-22).

Quando perguntado aos educandos do $6^{\circ}$ e do $9^{\circ}$ ano se os mesmos já haviam visitado o PEE, as respostas indicam que apenas $14,28 \%$ (2) e $23,52 \%$ (4) dos estudantes do 60 e 90 ano respectivamente, haviam visitado o local. Faz-se necessário registrar que o PEE se localiza a menos 
de $10 \mathrm{~km}$ da escola e que as visitas organizadas pela escola são limitadas, de acordo com a (Figura 2), as visitas escolares são inferiores, se comparadas com as visitas realizadas pelos estudantes de forma espontânea, sendo a porcentagem de visitas organizadas pela escola 7,14\% para o $6^{\circ}$ ano e $11,76 \%$ para o 90 ano. Estes valores permitem inferir que os estudantes não estão utilizando ou visitando o PEE com frequência, e que as escolas não fazem uso desta Unidade de Conservação como contexto para se discutir as questões relacionadas ao Bioma Pampa. Outrossim, estes dados evidenciam a necessidade de maior sensibilidade das escolas em desenvolver propostas de Educação Ambiental, partindo de questões regionais, que tenham significados para seus estudantes.

Figura 2 - Porcentagem de estudantes do $6^{\circ}$ e $9^{\circ}$ ano que já visitaram o PEE.

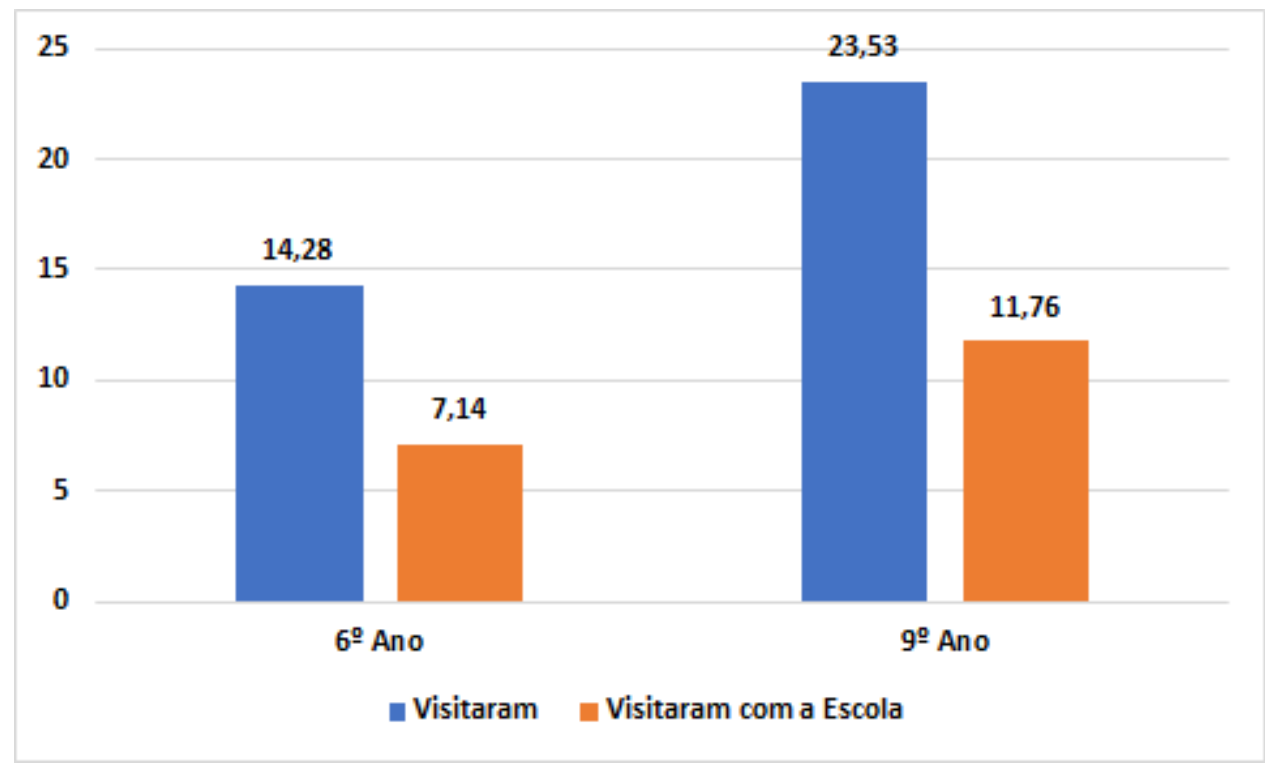

Fonte: Os autores.

Quando perguntado aos estudantes se acham importante à conservação do PEE, todos os estudantes (31), dos $6^{\circ}$ e $9^{\circ}$ ano responderam que sim, justificando da seguinte forma:

- Sim, porque lá tem plantas e animais que não existem em outro lugar;

- Porque eu acho um lugar importante, bastante chamativo, por ter "espinilhos" e também os animais que você não vê no dia a dia;

- Sim acho importante porque é uma reserva aonde se concentra aves, pássaros e a conservação desse local é muito importante para os animais, etc;

- Lá existem espécies importantes, de extrema beleza. Apesar de eu não conhecer o lugar, sempre me falaram muito bem de lá.

A partir destas e de outras respostas, pode-se discutir a falta de conhecimento in loco do PEE, com suposições, sendo algumas plausíveis e outras um tanto desconectadas com a realidade, como por exemplo:

- Lá existem espécies importantes, de extrema beleza. Apesar de eu não conhecer o lugar, sempre me falaram muito bem de lá;

- Porque as pessoas passam por lá e se não pegam doenças. 
Para finalizar essa primeira aproximação com os estudantes foi solicitado aos estudantes do $6^{\circ}$ ano, que realizassem um desenho sobre os seres vivos do PEE. O objetivo da atividade foi analisar a inserção da diversidade vegetal, ou dos vegetais enquanto conceito de ser vivo (Figuras 3 e 4).

\subsection{Percepções, expressões e concepções através dos desenhos}

O uso da técnica de desenhos dentro da educação básica possibilita aos educandos expressarem suas ideias através de uma linguagem simbólica. Nesse sentido, ao expressar suas concepções com o desenho, a criança vai inserindo um novo processo de aprendizagem, desenvolvendo suas habilidades cognitivas, levando esta criança a expressar através dos signos os sentidos particulares, significados e expressões reais e imaginárias (VYGOTSKY, 1991).

Figura 3 - Desenhos representando a vegetação do parque na visão de alguns estudantes.
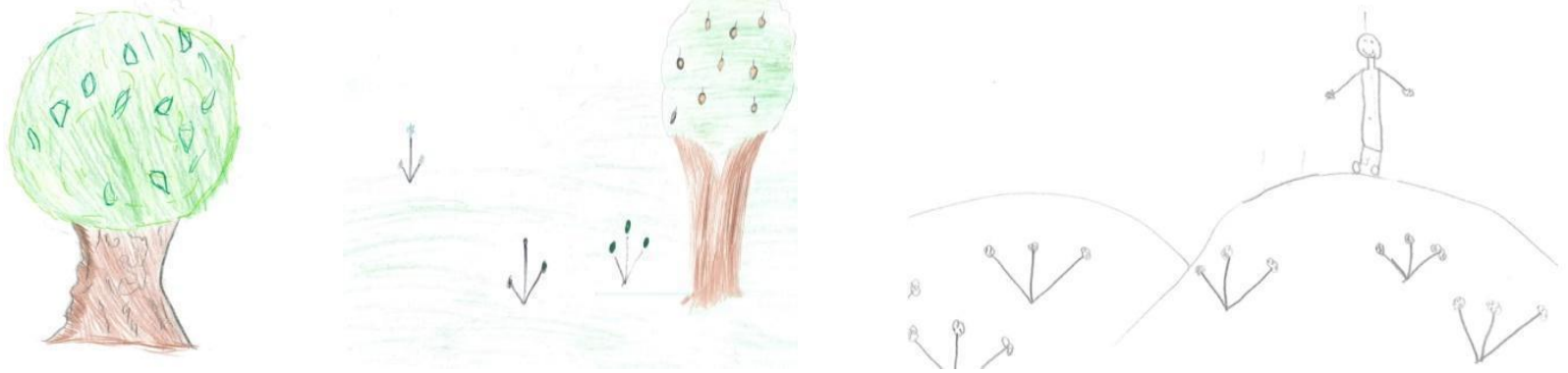

Fonte: desenhos realizados pelos estudantes.

As árvores espaçadas, a presença de vegetação herbácea (Figura 3) demonstra que os educandos possuem uma concepção de vegetação do seu entorno, o que pode ser justificado pela proximidade da sede município da Barra do Quaraí com o Parque Estadual do Espinilho, ou seja, os estudantes, de certo modo mantém contato mesmo que superficialmente com o parque, pois observam o seu entorno, já que o mesmo é cortado pela BR 472, que dá acesso ao município.

Faz-se necessário registrar que a maioria dos estudantes representaram um "ser vivo" com desenhos de animais (Figura 4). Porém, os desenhos expressam o conhecimento de animais nativos e exóticos, não pertencentes ao bioma Pampa, como o veado, a onça-pintada e o javali, sem apresentarem em seus desenhos, a fauna pertencente ao PEE e ao Bioma Pampa.

Figura 4 - Desenhos demonstrando a concepção de seres vivos - estudantes do $6^{\circ}$ ano.
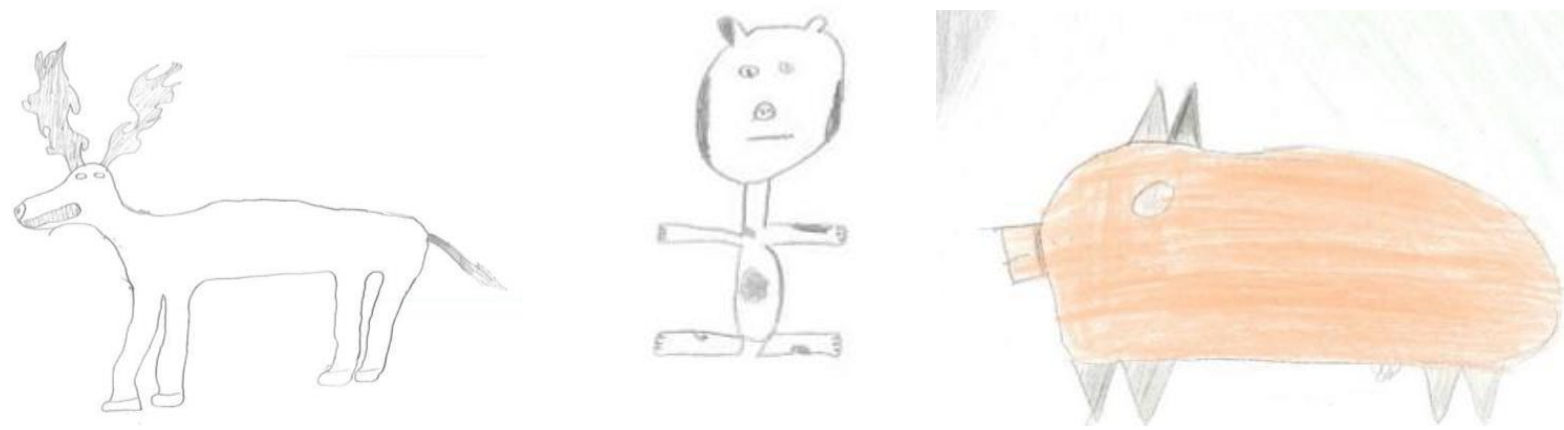

Fonte: desenhos realizados pelos estudantes.

Esta inclinação para o desenho de animais, como representante de seres vivos pode ser entendida como Cegueira Botânica. Segundo Corrêa (2020), Cegueira Botânica (CB), significa: 
[...] a incapacidade de ver as plantas, tendo como consequência a incapacidade de reconhecer sua importância, tanto na biosfera quanto para os seres humanos, além da incapacidade da apreciação estética e das formas biológicas únicas do reino ao qual fazem parte (CORRÊA, 2020, p. 10).

Para Macedo e Ursi (2016), o estudo das Ciências Naturais faz-se presente desde muito cedo na vida escolar de uma criança. Porém, com o amadurecimento, as aulas de Ciências tendem, muitas vezes, a tornarem-se desinteressantes e enfadonhas, devido ao caráter descritivo e técnico que assumem com o passar dos anos.

Segundo as autoras:

Dentro da grande área das Ciências Biológicas, podemos exemplificar o crescente desinteresse acima relatado quando falamos em Ensino de Botânica. Infelizmente, na maioria das vezes, as aulas são vistas como extremamente teóricas e desestimulantes, o que prejudica o ensino, aumentando a desvalorização em relação às plantas (MACEDO; URSI, 2016, p. 2723).

Após esta primeira análise, é possível inferir a urgência em se estabelecer o contato dos educandos diretamente com o Parque Estadual do Espinilho, promovendo a familiaridade destes com a diversidade vegetal do Bioma Pampa, promovendo neste espaço não formal de educação a possibilidade de práticas de ensino e aprendizagem de Educação Ambiental e Ciências da Natureza.

Entendemos que as atividades de Educação Ambiental desenvolvidas no PEE promoverão a formação do senso crítico dos estudantes, pois agregará a construção de aprendizagens significativas, a partir dos elementos naturais presentes neste espaço.

Ressalta-se que a atividade desenvolvida, visa colaborar com a análise da compreensão prévia dos estudantes com relação ao seu entorno e que propostas como expedições de estudo, fundamentadas no princípio da pesquisa como um potencializador da aprendizagem irão colaborar significativamente com as interações humanas com o meio ambiente.

\section{CONSIDERAÇÕES FINAIS}

Com os resultados prévios, foi possível inferir que os estudantes possuem conhecimentos incorretos e incompletos sobre o Bioma Pampa e mais especificamente sobre o PEE, com uma visão muito limitada sobre as suas potencialidades enquanto importante espaço de conservação.

Que o PEE não é utilizado enquanto espaço de ensino pela escola, visto que quase não houve registros de visitas ao parque a partir de projetos da escola e que com isso os estudantes possuem uma visão distorcida desta UC, com a ideia de que esta nada mais é do que um espaço com árvores, com alguns animais, que na maioria dos registros, são exóticos ao Pampa.

Sendo assim, faz-se necessário o desenvolvimento de projetos que envolvam o Parque Estadual do Espinilho como instrumento para a promoção da Educação Ambiental, possibilitando a reflexão sobre as questões regionais, a partir da biodiversidade vegetal e animal e da importância desta UC enquanto cenário para ensino e pesquisa. 


\section{REFERÊNCIAS}

BILENCA, D. N.; MIÑARRO, F. Identificación de Áreas Valiosas de Pastizal (AVPs) en las Pampas y Campos de Argentina, Uruguay y sur de Brasil. Buenos Aires: Fundación Vida Silvestre, 2004.

BOLDRINI, I. I.; FERREIRA, P. M. A.; ANDRADE, B. O.; SCHNEIDER, A. A.; SETUBAL, R. B.; TREVISAN, R.; FREITAS, E. M. Bioma Pampa: diversidade florística e fisionômica. Porto Alegre: Pallotti, 2010.

BOLDRINI, I. I.; POSER, G. L. V.; ZUANAZZI, J. A. S. Pampa. Biodiversidade e Produtos Naturais, 2010. Disponível em: http://inct-bionat.iq.unesp.br/biomas/bioma-pampa/. Acesso em: 12 dez. 2021.

BRASIL. Lei no 9.985, de 18 de julho de 2000. Institui o Sistema Nacional de Unidades de Conservação da Natureza. Diário Oficial da República Federativa do Brasil, Brasília, DF, 18 jul. 2000. Disponível em: http://www.planalto.gov.br/ccivil_03/leis/L9985.htm. Acesso em: 28 ago. 2018.

BRASIL. Ministério do Meio Ambiente. Biodiversidade Brasileira. Disponível em http://www.mma.gov.br/biodiversidade/biodiversidade-brasileira. Acesso em: 22 jul. 2020.

BRASIL. Ministério do Meio Ambiente. Pampa. Brasília, DF, 2010. Disponível em: https://antigo.mma.gov.br/biomas/pampa.html. Acesso em: 12 dez. 2021.

BRASIL. Vocabulário Básico de Recursos Naturais e Meio Ambiente. Instituto Brasileiro de Geografia e Estatística - IBGE. 2. ed. Rio de Janeiro: IBGE, 2004. Disponível em: https://biblioteca.ibge.gov.br/visualizacao/livros/liv4730.pdf. Acesso em: 20 set. 2020.

BRUSCA, R. C.; BRUSCA, G. J. Zoologia de Invertebrados. 2. ed. Rio de Janeiro: Guanabara Koogan, 2005.

CAMINHA, A. F. Ministério do Meio Ambiente. A Biodiversidade pouco conhecida do Pampa. Brasília, DF, 18 de outubro de 2010. Disponível em: https://www.gov.br/mma/pt-br/noticias/abiodiversidade-pouco-conhecida-do-pampa. Acesso em: 22 jul. 2020.

CASTRO, L. R. B. O Bioma Pampa como temática de investigação no ensino básico no município de Uruguaiana-RS. 2018. 180 f. Dissertação (Mestrado) - Programa de Pósgraduação em Educação em Ciências: Química da Vida e Saúde, Universidade Federal de Santa Maria, Santa Maria, 2017. Disponível em:

http://pgeec.ufsm.br/images/producoes/2016/dissertacoes/2017/2018/DISSERTACAO_LRBC.pdf. Acesso em: 16 jul. 2018.

CERATI, T. M.; LAZARINI, R. A. M. A Pesquisa-ação em Educação Ambiental: Uma Experiência no Entorno de uma Unidade de Conservação Urbana. Ciência e Educação, v. 15, n. 2, p. 383-92, 2009. Disponível em: https://doi.org/10.1590/S1516-73132009000200009. Acesso em: 28 out. 2020.

CORRÊA, A. M. Investigando, prevenindo e tratando a cegueira botânica em diferentes cenários do estado do Rio de Janeiro. 2020. 262 f. Tese (Doutorado) - Programa de Pósgraduação em Ensino em Biociências e Saúde, Fundação Oswaldo Cruz (FIOCRUZ), Rio de Janeiro. Biblioteca Depositária: Biblioteca de Ciências Biomédicas, 2020. Disponível em: https://www.arca.fiocruz.br/handle/icict/47389. Acesso em: 16 nov. 2020. 
CORREA, M. L. Origem do Descaso com o Bioma Pampa. 2008. 134 f. Monografia.

(Especialização) - Especialização em Educação Ambiental, Centro Universitário La Salle, Canoas/RS. 2008.

DINARDI, A. J.; FEIFFER, A. H. S.; FELIPPELLI, H. E. O Uso de Praças Públicas como Espaço não formal de Educação. Educação, Cultura e Sociedade, v. 8, n. 1, p. 311-326, 2018. Disponível em: http://sinop.unemat.br/projetos/revista/index.php/educacao/article/view/3053. Acesso em: 28 out. 2020.

FONSECA, M; LAMAS I.; KASECKER T. O Papel das unidades de conservação. Scientific American Brasil, v. 39, p. 18-23, 2010. Disponível em:

https://www.researchgate.net/publication/260513394_O_Papel_das_Unidades_de_Conservacao. Acesso em: 06 nov. 2020.

GALVANI, F. R.; BAPTISTA, L. R. de M. Flora do Parque Estadual do Espinilho - Barra do Quaraí/RS. Revista da FZVA, Uruguaiana, v.10, n.1, p.42-62, 2003.

HEIDEN, G.; IGANCI, J. R. Sobre a paisagem e a flora In: Elisabeth Regina Tempel Stumpf, Rosa Lia Barbieri e Gustavo Heiden (Org.). Cores e formas no Bioma Pampa plantas ornamentais nativas. Brasília: Embrapa, 2016.

KUPLICH, T. M.; CAPOANA, V.; COSTA, L. F. F. O Avanço da Soja no Bioma Pampa. Boletim Geográfico do Rio Grande do Sul, n. 31, p. 83-100, 2018. Disponível em: https://revistas.planejamento.rs.gov.br/index.php/boletim-geografico-rs/article/view/4102. Acesso em: 17 jul. 2020.

MACEDO, M.; URSI, S. Botânica na escola: uma proposta para o ensino de histologia vegetal. Revista da SBEnBio, v. 9, p. 2723-2733, 2016. Disponível em: http://botanicaonline.com.br/geral/arquivos/macedo\%20e\%20Ursi\%202016.pdf. Acesso em: 06 out. 2020.

MACHADO, M.; MENEZES, M. O. T.; SANTOS, M. R.; PRIETO, P. V.; HERING, R. L. O.; BARROS, F. S. M.; BORGES, R. A. X.; KUTSCHENKO, D. C.; VALENTE, A. S. M. Cactaceae. In: MARTINELLI, G.; MORAES, M. A. Livro vermelho da flora do Brasil. 1. ed. Rio de Janeiro: Instituto de Pesquisas Jardim Botânico do Rio de Janeiro, 2013.

MANDIÃO, A. G. Campos e areais no sudoeste do RS subsídios para a criação de Unidades de Conservação. 2012. 112 f. Dissertação (Mestrado) - Programa de Pós-graduação em Geografia, Universidade Federal do Rio Grande do Sul, Porto Alegre, 2012. Disponível em:https://www.lume.ufrgs.br/bitstream/handle/10183/67652/000873484.pdf?sequence=1\&isAllow ed=y . Acesso em: 28 out. 2020.

MARCHIORI, J. N. C.; ALVES, F. S.; DEBLE, L. P.; DEBLE, A. S. O. A vegetação do Parque Estadual Do Espinilho: Origem do nome e considerações Fitogeográficas. Balduinia, n. 44, p. 01-16, 2014. Disponível em: https://periodicos.ufsm.br/balduinia/article/view/14000. Acesso em: 05. jul. 2020.

MARTINS, S. F. A.; GARCIA, C. L. O Desenho no Ensino Fundamental. In: Secretaria da Educação do Paraná-PR. Os desafios da escola pública paranaense na perspectiva do Professor PDE. Paraná-PR: Cadernos PDE, 2014.

MEDEIROS, A. B.; MENDONÇA, Maria José da Silva Lemes; SOUSA, Gláucia Lourenço de; OLIVEIRA, Itamar Pereira de. A Importância da educação ambiental na escola nas séries iniciais. Revista

Faculdade Montes Belos, v. 4, n. 1, p. 1-17, 2011. Disponível em:

http://revista.fmb.edu.br/index.php/fmb/article/view/30. Acesso em: 18 out. 2020. 
MINAYO, M. C. S. (Org.). Pesquisa social: teoria, método e criatividade. Petrópolis-RJ: Vozes. 2010.

MOREIRA, M. A. Metodologias de Pesquisa em Ensino. São Paulo: Livraria da Física, 2011.

MOTA, J. C.; COUSIN, C. S.; KITZMANN, D. I. S. A Educação Ambiental Estética e as Relações de Pertencimento no Processo de Ambientalização Curricular. Revista Pedagógica, v. 20, n. 45, p. 207-226, 2018. Disponível em: https://doi.org/10.22196/rp.v20i45.3986. Acesso em: 28 out. 2020.

PILLAR, A. D. Desenho e escrita como sistemas de representação. 2. ed. Porto Alegre: Penso, 2012.

RICKLEFS, R. A Economia da Natureza. Tradução de Pedro Paulo de Lima e Silva. 6. ed. Rio de Janeiro: Guanabara Koogan, 2011.

RIO GRANDE DO SUL. Decreto $n^{\circ} 41.440$, de 28 de fevereiro de 2002. Amplia o Parque

Estadual do Espinilho, e dá outras providências. Governo do Estado do Rio Grande do Sul, Porto Alegre, RS, 2002. Disponível em:

https://www.icmbio.gov.br/cepsul/images/stories/legislacao/Decretos/2002/dec_rs_41440_2002_uc _parqueespinilho_rs.pdf. Acesso em: 12 dez. 2021.

RIO GRANDE DO SUL. Decreto n 53.037, de 20 de maio de 2016. Institui e regulamenta o Sistema Estadual de Unidades de Conservação - SEUC. Governo do Estado do Rio Grande do Sul, Porto Alegre, RS, 2016. Disponível em:

http://www.al.rs.gov.br/filerepository/repLegis/arquivos/DEC\%2053.037.pdf. Acesso em: 20 out. 2020.

RIO GRANDE DO SUL. Lei n 15.434, de 9 de janeiro de 2020. Institui o Código Estadual do Meio Ambiente do Estado do Rio Grande do Sul. Governo do Estado do Rio Grande do Sul, Porto Alegre, RS, 2020. Disponível em:

http://www.al.rs.gov.br/legis/M010/M0100099.ASP?Hid_Tipo=TEXTO\&Hid_TodasNormas=65984\&h Texto=\&Hid_IDNorma=65984. Acesso em: 06 nov. 2020.

SAUVÉ, L. Uma cartografia das correntes em Educação Ambiental. In: SATO, M.; CARVALHO, I. C. M. (Orgs.). Educação Ambiental - pesquisas e desafios. Porto Alegre: Artmed, 2005.

SOUZA, D. V. DINARDI, A. J. PEREIRA, K. B. Bioma Pampa: Compreensões prévias de alunos do Ensino Fundamental de duas escolas com diferente perfil socioambiental de Alegrete-RS. Revista Educação, Cultura e Sociedade, v. 10, n. 3, p. 440-455, 2020. Disponível em: http://sinop.unemat.br/projetos/revista/index.php/educacao/article/view/3957. Acesso em: 29 out. 2020.

VYGOTSKY, L. A formação social da mente: o desenvolvimento dos processos superiores. 4. ed. São Paulo: Martins Fontes, 1991.

Submissão: 23/09/2021

Aceito:14/12/2021 